\title{
STUDI KELAYAKAN KAPASITAS TAMPUNG DRAINASE JALAN FRANS KAISEPO KELURAHAN MALAINGKEDI KOTA SORONG
}

\author{
Ahmad Fauzan ${ }^{1)}$, Hendrik Pristianto ${ }^{2)}$ \\ 1) Mahasiswa Fakultas Teknik Sipil Universitas Muhammadiyah Sorong \\ 2) Dosen Program Studi Teknik Sipil Universitas Muhammadiyah Sorong
}

Diterima:23 Agustus 2017. Disetujui:20 September 2017. Dipublikasikan:1 Oktober 2017

\begin{abstract}
ABSTRAK
Kondisi dari keadaan di kawasan Jalan Frans Kaisepo Kelurahan Malaingkedi Kota Sorong. Hampir setiap tahun pada musim penghujan air meluap dari saluran drainase, sehingga terjadi genangan/banjir yang mengganggu aktivitas masyarakat. Berdasarkan identifikasi, genangan yang terjadi disebabkan oleh karena banyaknya sedimentasi sampah dan material bangunan di dalam saluran tersebut, sehingga air di dalam saluran drainase tidak mengalir dan kapasitas saluran drainase yang tidak mampu menampung akumulasi air hujan. Tujuan penelitian ini untuk mengetahui kapasitas tampung drainase dan untuk mengetahui penyebab banjir, serta mencari solusinya. Setelah curah hujan maksimum didapat, maka dilanjutkan dengan perhitungan intensitas curah hujan. Selanjutnya perhitungan standar deviasi untuk mendapatkan perhitungan kala ulang dengan menggunakan metode log person type III. Dari perhitungan periode ulang tersebut, baru dilakukan perhitungan debit saluran yang ada. Dari analisa yang telah dilakukan, kapasitas saluran tanpa adanya sedimentasi kondisi optimalnya didapat saluran ruas kanan mampu menampung 92.81\%, saluran ruas kiri mampu menampung $73.31 \%$ intensitas hujan 2 tahun. Saluran ruas Kanan mampu menampung $72.02 \%$ dan ruas kiri mampu menampung $56.91 \%$ akibat intensitas hujan periode ulang 5 tahun. Saluran kanan mampu menampung $63.10 \%$ sedangkan kiri mampu menampung $49.08 \%$ akibat intensitas hujan periode ulang 10 tahun. debit banjir periode ulang untuk ruas jalan Frans Kaisepo di dapat: Ruas kanan : $\mathrm{Q}_{2}=2.82 \mathrm{~m}^{3} / \mathrm{dtk}, \mathrm{Q}_{2}=3.64 \mathrm{~m}^{3} / \mathrm{dtk}$, dan $\mathrm{Q}_{10}=4.15$ $\mathrm{m}^{3} / \mathrm{dtk}$. Ruas kiri : $\mathrm{Q}_{2}=4.33 \mathrm{~m}^{3} / \mathrm{dtk}, \mathrm{Q}_{5}=5.58 \mathrm{~m}^{3} / \mathrm{dtk}$, dan $\mathrm{Q}_{10}=6.37 \mathrm{~m}^{3} / \mathrm{dtk}$. Jadi Untuk mengatasi genangan yang ada pada ruas jalan tersebut perlu dilakukan pengerukkan/pembersihan sedimentasi terhadap saluran drainase yang ada sehingga bisa menampung $\mathrm{Q}_{2 \text { th }}, \mathrm{Q}_{5 \text { th dan }} \mathrm{Q}_{10 \text { th }}$ terhadap drainase ruas kanan, ruas kiri hanya bisa menampung $\mathrm{Q}_{2 \text { th. }}$ Sehingga drainase ruas kiri harus desain penampang baru agar bisa menampung $\mathrm{Q}_{5 \text { th dan }} \mathrm{Q}_{10 \text { th. }}$
\end{abstract}

Kata kunci: Drainase, Intensitas, Debit

\section{PENDAHULUAN}

\subsection{Latar Belakang}

Pesatnya perkembangan Kota Sorong dari tahun ketahun menyebabkan berubahnya karakteristik fisik Kota Sorong. Ditinjau dari tersedianya sarana dan prasarana drainase Kota Sorong yang ada, penanganan drainase saat ini kurang memadai, dimana hal tersebut dapat dilihat dari masih banyaknya terjadi banjir/genangan air hujan yang menggenangi pemukiman dan jalan.

Faktor - faktor di atas terjadi disebabkan oleh kurangnya penataan drainase, perencanaan drainase yang kurang terarah, kesadaran masyarakat dalam melakukan pemeliharaan drainase dan lingkungannya.

Pada kajian ini yang akan diangkat adalah kondisi dari keadaan di kawasan Jalan Frans Kaisepo Kelurahan Malaingkedi Kota Sorong. Dipilihnya lokasi ini karena hampir setiap tahun pada musim penghujan air meluap dari saluran drainase, sehingga terjadi genangan air bahkan sering terjadi banjir yang mengganggu aktivitas masyarakat. Secara sekilas kondisi eksisting saluran drainase yang terdapat dilokasi studi memang kurang cukup memadai.

\subsection{Tujuan Penelitian}


Tujuan yang ingin dicapai oleh penyusun dalam hal ini adalah sebagai berikut:

1. Untuk mengetahui kapasitas tampung saluran drainase pada Jalan Frans Kaisepo Kelurahan Malaingkedi Kota Sorong.

2. Untuk mengetahui penyebab banjir dan mencari solusi mengatasi genangan air di Jalan Frans Kaisepo Kota Sorong serta mendesain alternatif penampang saluran drainase.

\section{METODOLOGI PENELITIAN}

\subsection{Lokasi Penelitian}

Tinjauan lokasi penelitian ini di Jalan Frans Kaisepo Kelurahan Malaingkedi Kota Sorong. Adapun lokasi penelitian ini dapat dilihat pada gambar berikut.

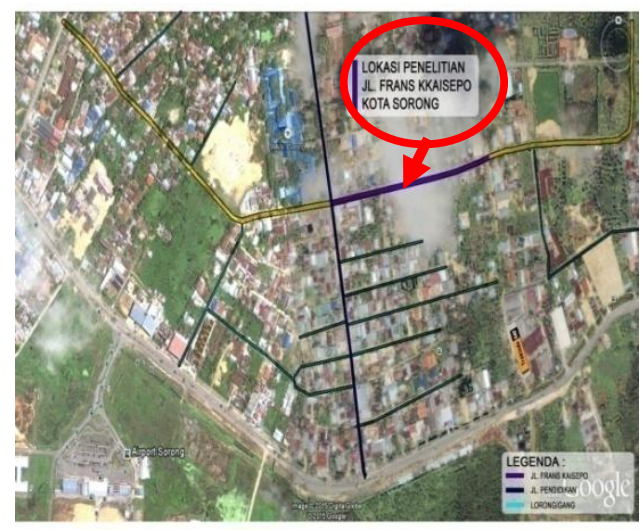

Gambar 1. Lokasi Penelitian

\subsection{Pengamatan Langsung Dilapangan}

Pengamatan survei lapangan awal dilakukan untuk mendapat gambaran mengenai drainase di wilayah studi . Survei awal ini lebih dititik beratkan untuk hal yang berkaitan dengan sistem drainase dan menerima masukan untuk penentuan daerah prioritas penanganan.

\subsection{Metode Pengumpulan Data}

Penelitian ini menggunakan metode deskriptif dengan menggunakan data sekunder dan peta.

\subsection{Metode Analisis Data}

Analisis data akan dilakukan berdasarkan ketersediaan data yang diperoleh dari pengumpulan data yang telah dilaksanakan. Pada saat pengumpulan data, didapatkan data :

a. Analisa hidrologi (analisa data curah hujan, hujan rencana dan perhitungan debit rencana)

b. Analisa Hidrolika terhadap Q2,Q5 dan Q10

c. Alternative Design jika tidak aman terhadap Q2,Q5 dan Q10.

d. Untuk Analisis debit banjir rencana menggunakan metode Rasional

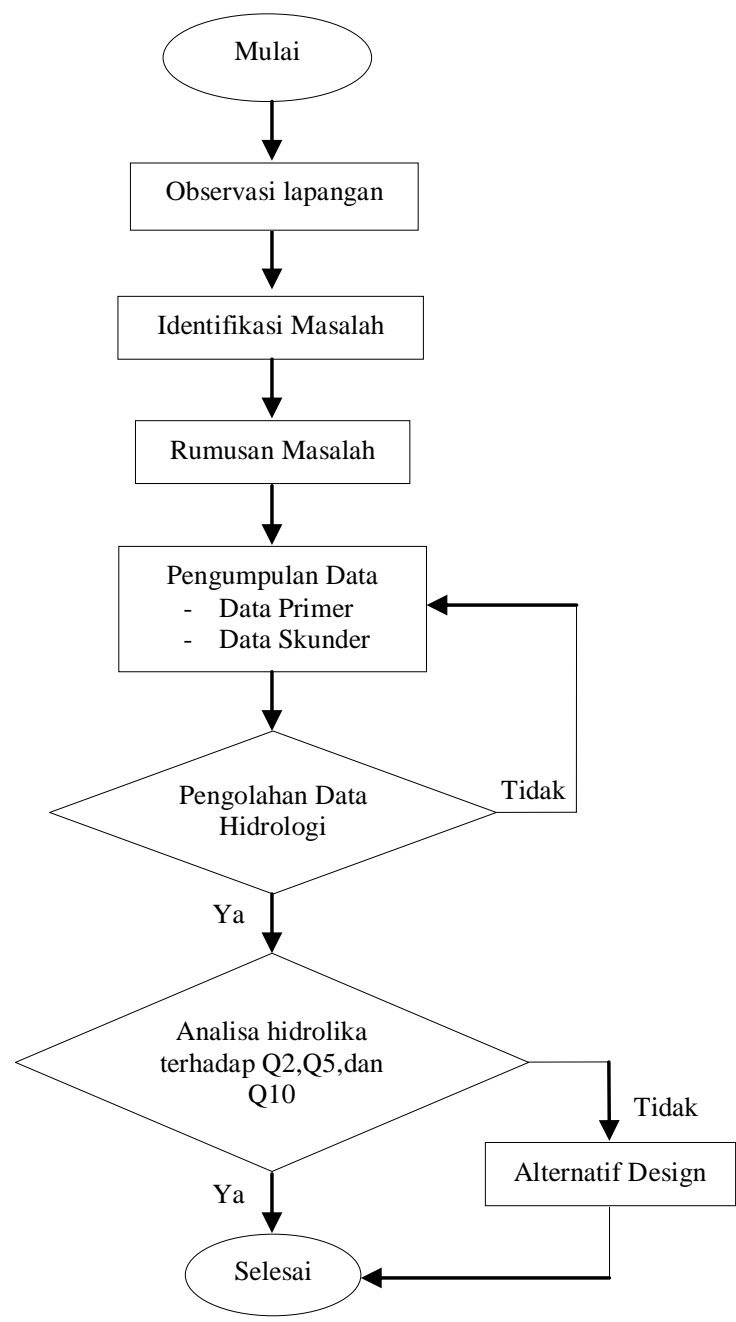

Bagan 2. Flowchart alir penelitian

\section{PEMBAHASAN}

\subsection{Analisis Curah Hujan Daerah Studi}

Data curah hujan yang digunakan selama 11 tahun, dari tahun 2004 hingga tahun 2014. Data ini merupakan penggabungan data primer yang diperoleh dari BMKG Sorong untuk stasiun Bandara Jefman dan Bandara DEO Sorong yang 
selanjutnya disebut sebagai Data Curah Hujan Bulanan BMKG Sorong. 


\section{Jurnal Rancang Bangun 3(1) 28-34 2017}

Tabel 1. Data Curah Hujan BMKG Sorong

\begin{tabular}{||c|c|c|c|c|c|c|c|c|c|c|c||}
\hline BULAN & $\mathbf{2 0 0 4}$ & $\mathbf{2 0 0 5}$ & $\mathbf{2 0 0 6}$ & $\mathbf{2 0 0 7}$ & $\mathbf{2 0 0 8}$ & $\mathbf{2 0 0 9}$ & $\mathbf{2 0 1 0}$ & $\mathbf{2 0 1 1}$ & $\mathbf{2 0 1 2}$ & $\mathbf{2 0 1 3}$ & $\mathbf{2 0 1 4}$ \\
\hline \hline JAN & 204 & 55 & 254 & 253 & 140 & 176 & 63 & 123 & 219 & 221 & 125 \\
\hline FEB & 157 & 75 & 118 & 143 & 232 & 200 & 77 & 301 & 195 & 200 & 127 \\
\hline MAR & 149 & 132 & 99 & 262 & 337 & 274 & 61 & 467 & $\mathbf{5 8 2}$ & 155 & 203 \\
\hline APR & 272 & 266 & 52 & 321 & 201 & 371 & 193 & 187 & 276 & 357 & 88 \\
\hline MEI & 142 & 239 & 8 & 322 & 430 & 126 & 100 & 133 & 179 & $\mathbf{6 6 1}$ & $\mathbf{5 0 6}$ \\
\hline JUN & 93 & $\mathbf{3 8 5}$ & 9 & 538 & 404 & 296 & 80 & 205 & 444 & 171 & 341 \\
\hline JUL & 189 & 228 & 183 & $\mathbf{9 2 1}$ & 597 & $\mathbf{3 9 1}$ & 358 & $\mathbf{6 0 0}$ & 456 & 491 & 106 \\
\hline AGUS & 24 & 136 & 8 & 276 & $\mathbf{6 1 4}$ & 150 & $\mathbf{5 9 2}$ & 469 & 348 & 284 & 355 \\
\hline SEPT & $\mathbf{3 3 8}$ & 113 & $\mathbf{3 8 6}$ & 301 & 417 & 132 & 471 & 399 & 191 & 221 & 96 \\
\hline OKT & 64 & 370 & 7 & 450 & 379 & 86 & 345 & 176 & 119 & 122 & 73 \\
\hline NOV & 161 & 186 & 74 & 230 & 309 & 281 & 231 & 243 & 175 & 247 & 235 \\
\hline DES & 257 & 342 & 21 & 407 & 245 & 74 & 339 & 243 & 150 & 219 & 198 \\
\hline R MAX & $\mathbf{3 3 8}$ & $\mathbf{3 8 5}$ & $\mathbf{3 8 6}$ & $\mathbf{9 2 1}$ & $\mathbf{6 1 4}$ & $\mathbf{3 9 1}$ & $\mathbf{5 9 2}$ & $\mathbf{6 0 0}$ & $\mathbf{5 8 2}$ & $\mathbf{6 6 1}$ & $\mathbf{5 0 6}$ \\
\hline
\end{tabular}

Sumber : Badan Meteorologi Klimatologi dan Geofisika kota Sorong

Tabel 2. Perhitungan Statistik Data Hujan

\begin{tabular}{||c|c|c|c|c|c|c||}
\hline \hline No & TAHUN & $\begin{array}{c}\text { X } \\
(\mathrm{mm})\end{array}$ & $(\mathrm{X}-\mathrm{Xrt})$ & $(\mathrm{X}-\mathrm{Xrt})^{2}$ & $(\mathrm{X}-\mathrm{Xrt})^{3}$ & $(\mathrm{X}-\mathrm{Xrt})^{4}$ \\
\hline \hline 1 & 2007 & 921 & 377,73 & 142677,89 & 53893331,24 & 23069766211,34 \\
\hline 2 & 2013 & 661 & 117,73 & 13859,71 & 1631665,95 & 283220804,33 \\
\hline 3 & 2008 & 614 & 70,73 & 5002,35 & 353802,37 & 46837621,06 \\
\hline 4 & 2011 & 600 & 56,73 & 3217,98 & 182547,43 & 22310866,70 \\
\hline 5 & 2010 & 592 & 48,73 & 2374,35 & 115695,46 & 1359981,03 \\
\hline 6 & 2012 & 582 & 38,73 & 1499,80 & 58083,23 & 6621647,46 \\
\hline 7 & 2014 & 506 & $-37,27$ & 1389,26 & $-51781,37$ & 407951,41 \\
\hline 8 & 2009 & 391 & $-152,27$ & 23186,98 & $-3530745,21$ & 387162213,02 \\
\hline 9 & 2006 & 386 & $-157,27$ & 24734,71 & $-3890095,42$ & 457776438,23 \\
\hline 10 & 2005 & 385 & $-158,27$ & 25050,26 & $-3964772,37$ & 1395347247,82 \\
\hline 11 & 2004 & 338 & $-205,27$ & 42136,89 & $-8649554,85$ & 5910559814,90 \\
\hline \multicolumn{2}{|c|}{ Jumlah } & 5976 & 0 & 285130,18 & 36148176,45 & 24146743632,45 \\
\hline
\end{tabular}

Sumber; Hasil Perhitungan 2015

Hujan harian rata - rata $($ Xrt $)=\frac{5976}{11}$

$$
=543,27 \mathrm{~mm}
$$

Standar deviasi $(\sigma)$

$=\sqrt{\frac{\sum(X-X r t)^{2}}{(n-1)}}=\sqrt{\frac{285130,18}{11-1}}$
$=168,8580$
Koefisien Variasi ( Cv )

$$
=\frac{\sigma}{\mathrm{Xrt}}=\frac{168,858}{543,27}=0,3108
$$

Koefisien kemencengan ( Cs )

$=\frac{n}{(n-1)(n-2) \sigma^{3}} \sum_{i-1}^{n}(\mathrm{X}-\mathrm{Xrt})^{3}$ 


\section{Jurnal Rancang Bangun 3(1) 28-34 2017}

$$
\begin{aligned}
& =\frac{11}{(11-1)(11-2) 4814650,719} \quad(36148176,45) \\
& =0,9176 \\
& \text { Koefisien kortusis }(\mathrm{Ck}) \\
& \quad=\frac{n}{(n-1)(n-2)(n-3) \sigma^{4}} \sum_{i-1}^{n}(\mathrm{X}-\mathrm{Xrt})^{4} \\
& =\frac{11}{(11-1)(11-2)(11-3) 812992205,85} \\
& \\
& \quad(24146743632,45) \\
& =0,4538
\end{aligned}
$$

Nilai $\mathrm{Ck}$ memenuhi syarat perhitungan statistik ( $\mathrm{Ck}>0$ ) dengan nilai $\mathrm{Cs}=0,9176$ memenuhi syarat ( kriteria Cs $=$ bebas $)$.

\subsection{Intensitas Curah Hujan}

Menurut Loebis (1992), intensitas hujan $(\mathrm{mm} / \mathrm{jam})$ dapat diturunkan dari data curah hujan harian $(\mathrm{mm})$ empiris menggunakan metode monobe, intensitas curah hujan $(I)$ dalam rumus rasional dapat dihitung berdasarkan rumus:

$$
I=\frac{R_{24}}{24}\left(\frac{24}{t}\right)^{2 / 3}
$$

$\mathrm{R}_{2}=$ curah hujan rencana wilayah Sorong dengan periode ulang 2 tahun $=521,011 \mathrm{~mm}$

$\mathrm{R}_{5}=$ curah hujan rencana wilayah Sorong dengan periode ulang 5 tahun $=671,140 \mathrm{~mm}$

$\mathrm{R}_{10}=$ curah hujan rencana wilayah Sorong dengan periode ulang 10 tahun $=766,328 \mathrm{~mm}$
Perhitungan Intensitas Hujan selama 5 Menit

$$
\begin{aligned}
& I_{2}=\frac{521,011}{24}\left(\frac{24}{0,08}\right)^{2 / 3}=946,740 \mathrm{~mm} / \mathrm{jam} \\
& \mathrm{I}_{5}=\frac{671,140}{24}\left(\frac{24}{0,08}\right)^{2 / 3}=1219,543 \mathrm{~mm} / \mathrm{jam} \\
& \mathrm{I}_{10}=\frac{766,328}{24}\left(\frac{24}{0,08}\right)^{2 / 3}=1392,511 \mathrm{~mm} / \mathrm{jam}
\end{aligned}
$$

\subsection{Perhitungan Debit Banjir Saluran yang akan Ditinjau}

Untuk menentukan debit rencana kita harus menentukan gambaran koefisien daerah aliran permukaan pada daerah studi pada titik-titik pengamatan didalam dan sekitar daerah yang dimaksud.

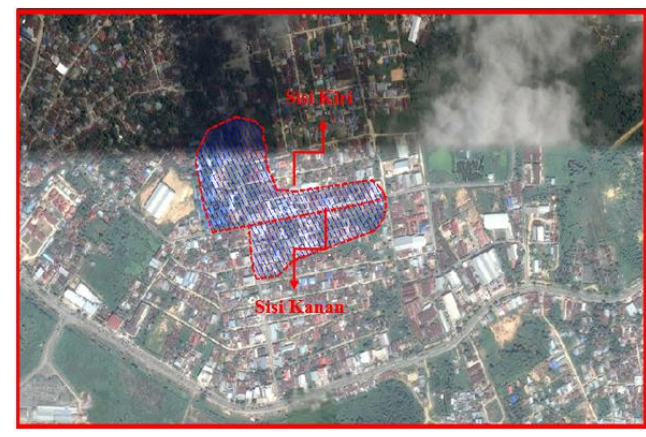

\begin{tabular}{|c|c|c|c|c|c|c|c|c|c|}
\hline \multirow{3}{*}{$\begin{array}{c}\text { Area } \\
\text { Pada } \\
\text { Jalan } \\
\text { Frans } \\
\text { Kaisepo }\end{array}$} & \multicolumn{4}{|c|}{ Luas Daerah, A (Hektar) } & \multirow{2}{*}{\multicolumn{4}{|c|}{$\begin{array}{c}\text { Koef. Pengaliran } \\
\text { (C) } \\
\text { Tabel. } 6\end{array}$}} & \multirow{3}{*}{$\begin{array}{l}\text { (C) } \\
\text { rerata } \\
\text { (i) }\end{array}$} \\
\hline & \multirow{2}{*}{$\begin{array}{c}\begin{array}{c}\text { Pemukiman } \\
\text { (rumah } \\
\text { tinggal) }\end{array} \\
\text { (a) }\end{array}$} & \multirow{2}{*}{$\begin{array}{c}\begin{array}{c}\text { Industri } \\
\text { (industri } \\
\text { ringan) }\end{array} \\
\text { (b) }\end{array}$} & \multirow[t]{2}{*}{$\begin{array}{c}\text { dengan tutupan } \\
\text { lahan } \\
\text { ( Jalan Asphalt } \\
\text { dan Beton) }\end{array}$} & \multirow[t]{2}{*}{$\begin{array}{c}\text { Tanpa } \\
\text { tutupan } \\
\text { Lahan }\end{array}$} & & & & & \\
\hline & & & & & (e) & (f) & (g) & (h) & \\
\hline $\begin{array}{c}\text { Sisi } \\
\text { Kanan } \\
\text { Jalan }\end{array}$ & 2,54 & 0,37 & 0,34 & 0,33 & 0,5 & 0.7 & 0,9 & 0,2 & 0,531 \\
\hline $\begin{array}{c}\text { Sisi kiri } \\
\text { Jalan }\end{array}$ & 3,33 & 0,36 & 0,75 & 1,14 & 0,5 & 0.7 & 0,9 & 0,2 & $\mathbf{0 , 5 0 5}$ \\
\hline Total & 5,87 & 0,73 & 1,09 & 1,473 & & & & & \\
\hline Luas $\mathrm{Da}$ & Cakupan & aase. & Frans Kaisepo & $=$ & & 9,16 & & $\mathrm{Ha}$ & \\
\hline
\end{tabular}

Gambar. Pembagian Beban Saluran Drainase di Daerah Studi

Dari gambar 10 di atas, kita bisa mendapatkan gambaran koefisien aliran permukaan pada daerah studi.

Tabel. Analisa Koefisien Pengaliran pada Daerah Tinjauan

Tabel. Analisa Koefisien Pengaliran pada Daerah Tinjauan

Sumber : Hasil Perhitungan 2015 


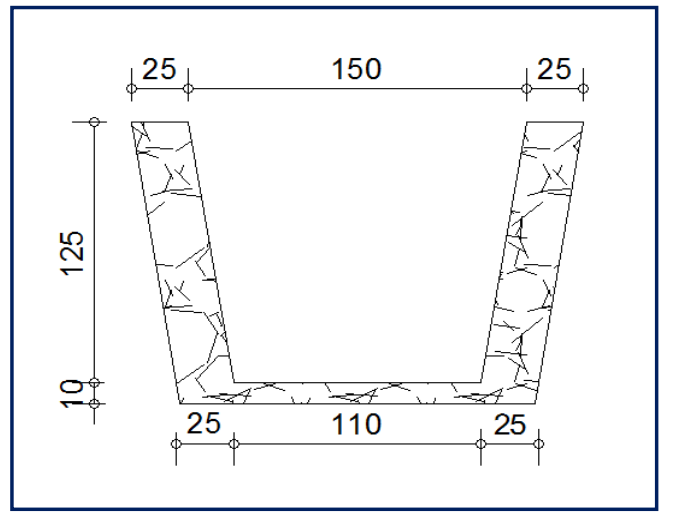

Gambar. Bentuk Penampang Existing Drainase Jalan Frans Kaisepo Ruas kanan

Perhitungan berdasarkan kondisi penampang Existing Drainase sebagai berikut :

Menghitung kemiringan talud (m) sebagai berikut:
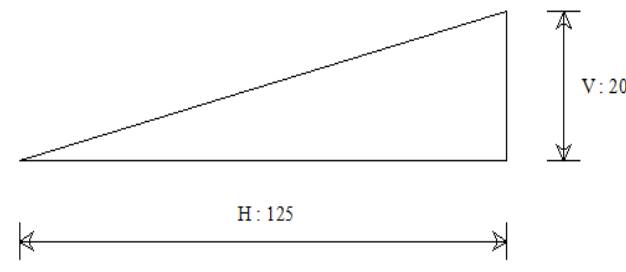

$\mathrm{m}=$ jarak vertical $:$ horizontal

$$
m=\frac{20}{125} \times 100 \%=16 \%
$$

Kecepatan rata- rata Drainase Jalan Frans Kaisepo ruas kanan

$$
\begin{aligned}
\mathrm{A} & =(\mathrm{b}+\mathrm{mh}) \cdot \mathrm{h}=(1,10+0,16 \cdot 1,25) 1,25 \\
& =1,63 \mathrm{~m}^{2} \\
\mathrm{P} & =\mathrm{b}+2 \mathrm{~h} \sqrt{1+\mathrm{m}^{2}}=1,10+2 \cdot(1,25) \\
& \sqrt{1+0,16^{2}}=3,63 \mathrm{~m} \\
\mathrm{R} & =\frac{\mathrm{A}}{\mathrm{P}}=\frac{1,63}{3,63}=0,447 \mathrm{~m} \\
\mathrm{~V} & =\frac{1}{\mathrm{n}} \cdot \mathrm{R}^{\frac{2}{3}} \cdot \mathrm{i}^{\frac{1}{2}}=\frac{1}{0.02} \cdot(0,447)^{\frac{2}{3}} \cdot(0,0028)^{\frac{1}{2}} \\
& =1.537 \mathrm{~m} / \mathrm{det} \\
\mathrm{Q} & =\mathrm{A} \cdot \mathrm{V}
\end{aligned}
$$

$=1,63 \cdot 1,537$

$=2,50 \mathrm{~m}^{3} / \mathrm{det}$

Waktu pengaliran sepanjang saluran Jalan Frans Kaisepo Ruas Kanan

$$
\begin{aligned}
\mathrm{t}_{\mathrm{d}} & =\left(\frac{\mathrm{Ls}}{60 \cdot \mathrm{V}}\right) \\
& =\left(\frac{350}{60 \cdot 1,537}\right) \\
& =3,795 \text { menit }
\end{aligned}
$$

Waktu Konsentrasi

$$
\begin{aligned}
\mathrm{t}_{\mathrm{c}} & =\text { to }+\mathrm{td} \\
& =5+3,795=8,795 \text { menit }
\end{aligned}
$$

Koefisien Penampungan

$$
\text { Cs } \quad=\frac{2 \text { tc }}{2 \text { tc }+ \text { td }}=\frac{2 \cdot(8,795)}{2 \cdot(8,795)+(3,795)}=0,823
$$

Intensitas hujan dalam 5 ( lima ) menit

$$
\begin{aligned}
\mathrm{I}_{2} & =\frac{\mathrm{R}_{2}}{24} \cdot\left(\frac{24}{\mathrm{t}}\right)^{\frac{2}{3}} \\
& =\frac{521,011}{24} \cdot\left(\frac{24}{8,795 / 60}\right)^{\frac{2}{3}} \\
& =649,721 \mathrm{~mm} / \mathrm{jam} \\
\mathrm{I}_{5} & =\frac{\mathrm{R}_{2}}{24} \cdot\left(\frac{24}{\mathrm{t}}\right)^{\frac{2}{3}} \\
& =\frac{671,140}{24} \cdot\left(\frac{24}{8,795 / 60}\right)^{\frac{2}{3}} \\
& =836 \cdot 938 \mathrm{~mm} / \mathrm{jam} \\
\mathrm{I}_{10} & =\frac{\mathrm{R}_{2}}{24} \cdot\left(\frac{24}{\mathrm{t}}\right)^{\frac{2}{3}} \\
& =\frac{766,328}{24} \cdot\left(\frac{24}{8,795 / 60}\right)^{\frac{2}{3}} \\
& =955,641 \mathrm{~mm} / \mathrm{jam}
\end{aligned}
$$

Debit air yang masuk dalam saluran

$$
\begin{aligned}
\mathrm{Q}_{2} & =0,00278 \times 0,531 \times 0,823 \times 649,721 \times 3,58 \\
& =2,82 \mathrm{~m}^{3} / \mathrm{det} \\
\mathrm{Q}_{5} & =0,00278 \times 0,531 \times 0,823 \times 836,938 \times 3,58 \\
& =3,64 \mathrm{~m}^{3} / \mathrm{det} \\
\mathrm{Q}_{10} & =0,00278 \times 0,531 \times 0,823 \times 955,641 \times 3,58 \\
& =4,15 \mathrm{~m}^{3} / \mathrm{det}
\end{aligned}
$$

\subsection{Perhitungan Kapasitas Saluran}

Untuk sistem drainase pada kedua ruas jalan, dari tata letaknya terlihat sangat mengandalkan keberadaan saluran pada kanan dan kiri jalan. Sehingga dalam hal ini, perlu dievaluasi apakah kapasitas salurannya masih mampu menampung debit limpasan yang berada di wilayah tersebut. 
Gambar. Daerah Tata Letak Saluran Drainase yang di Tinjau

\section{Kesimpulan}

1. Pada kondisi saat ini untuk kelayakan kapasitas tampung drainase jalan Frans Kaisepo, pada ruas kanan dan kiri tidak mampu menampung debit banjir periode ulang 2, 5, dan 10 dengan penampang drainase bersedimentasi. Setelah dianalisa penampang drainase dianggap tidak bersedimentasi untuk kelayakan kapasitas tampung drainase pada ruas kanan bisa menampung debit periode ulang 2, 5 dan $10 \mathrm{Th}$. Pada ruas kiri masih mampu menampung debit banjir periode ulang $2 \mathrm{Th}$. tetapi tidak bisa menampung debit banjir periode ulang 5 dan 10 Th.

Kondisi Drainase di sepanjang Jalan Frans Kaisepo adalah pada kondisi yang diasumsi tidak bersedimentasi kondisi optimalnya adalah:

a. Saluran kanan hanya mampu menampung sekitar 92,81\% sedangkan saluran kiri menampung $73,31 \%$ limpasan permukaan akibat intensitas hujan periode ulang 2 tahun dari masing masing catchment area-nya

b. Saluran kanan hanya mampu menampung sekitar 72,05\% sedangkan saluran kiri menampung $56,91 \%$ limpasan permukaan akibat intensitas hujan periode ulang 5 tahun dari masing masing catchment area-nya

c. Saluran kanan hanya mampu menampung sekitar 63,10\% sedangkan saluran kanan menampung $49.08 \%$ limpasan permukaan akibat intensitas hujan periode ulang 10 tahun dari masing masing catchment area-nya
2. Hasil perhitungan debit saluran untuk debit banjir periode ulang dengan menggunakan metode Rasional untuk ruas jalan Frans Kaisepo di dapat :

Ruas kanan : $\mathrm{Q}_{2 \text { th }}=2.82 \mathrm{~m}^{3} / \mathrm{dtk}, \mathrm{Q}_{5 \text { th }}=$ $3.64 \mathrm{~m}^{3} / \mathrm{dtk}$, dan $\mathrm{Q}_{10 \mathrm{th}}=4.15 \mathrm{~m}^{3} / \mathrm{dtk}$

Ruas kiri $: \mathrm{Q}_{2 \text { th }}=4.33 \mathrm{~m}^{3} / \mathrm{dtk}, \mathrm{Q}_{5 \text { th }}=$ $5.58 \mathrm{~m}^{3} / \mathrm{dtk}$, dan $\mathrm{Q}_{10 \mathrm{th}}=6.37 \mathrm{~m}^{3} / \mathrm{dtk}$

Dari debit banjir periode ulang yang diperoleh dari analisa perhitungan, maka terjadinya banjir dilapangan diakibatkan oleh kapasitas tampung yang tidak memadai karena tingginya sedimentasi yang ada pada drainase baik ruas kanan dan kiri jalan Frans Kaisepo. Oleh karena itu perlu adanya pengerukan sedimentasi agar drainase bisa menampung kapasitas debit banjir periode ulang $\mathrm{Q}_{2}, \mathrm{Q}_{5}$ dan $\mathrm{Q}_{10}$ pada saluran drainase ruas kanan. Untuk saluran ruas kiri jika sedimentasi dikeruk hanya mampu menampung kapasitas debit banjir periode ulang $\mathrm{Q}_{2}$. Setelah dianalisa dengan alternatif desain untuk $\mathrm{Q}_{5}$ dan $\mathrm{Q}_{10}$ pada saluran ruas kiri maka bisa menampung debit banjir apabila:

a. Untuk dimensi penampang periode ulang $\mathrm{Q}_{5 \text { th }}$ adalah:

Lebar dasar saluran (B)

$=1.80 \mathrm{~m}$

Tinggi Aliran (h)

$=1.40 \mathrm{~m}$

Tinggi jagaan $(\mathrm{F})$

$=0.24 \mathrm{~m}$

Kemiringan ijin saluarn

$=0.0031$

Koefisien kekasaran Manning

$=0.02$

Kemiringn talud (m)

$=0.16$

b. Untuk dimensi penampang periode ulang $\mathrm{Q}_{10 \mathrm{th}}$ adalah:

Lebar dasar saluran (B)

$=1.85 \mathrm{~m}$

Tinggi Aliran (h)

$=1.50 \mathrm{~m}$

Tinggi jagaan $(\mathrm{F})$

$=0.24 \mathrm{~m}$

Kemiringan ijin saluarn

$=0.0031$

Koefisien kekasaran Manning

$=0.02$

Kemiringn talud (m) 


$$
=0.16
$$

\section{DAFTAR PUSTAKA}

Departemen Pekerjaan Umum. Direktorat Jendral Cipta Karya, 2006. Materi Pelatihan Teknis Bidang PLP. Jakarta.

Departemen Pekerjaan Umum, 2006. Pedoman Perencanaan sitem Drainase Jalan. Pd. T-02-2006-B. Jakarta.

Departemen Pekerjaan Umum. Satker Pengembangan kinerja Penyehatan Lingkungan Pemukiman Sulawesi Selatan, 2008. Materi Diseminasi Dan Sosialisasi NSPM Bidang PLP. Makassar.

Departemen Pekerjaan Umum, 1998. Tata Cara Pembuatan Studi Kelayakan Drainase Perkotaan. CT/Dr/Re-Tc/98. Jakarta.

Departemen Pemukiman dan Prasarana Wilayah. Direktorat Jendral Tata Perkotaan, Tata pedesaan, 2003. Panduan dan Petunjuk Praktis Pengelolaan Drainase Perkotaan. Jakarta.

Hasmar Halim H.A., 2011. Drainase Terapan. Yogyakarta: UII press

Nastity yulia, 2013. Evaluasi Saluran Drainase Jalan Gaharu. Dikutip, April 16, 2015. Dari https:// www.academia.edu.

Suripin Ir., M.Eng., Dr., 2004. Sistim Drainase Perkotaan Yang Berkelanjutan. Yogyakarta: Andi.

Universitas Muhammadiyah Sorong, 2012. Modul Mata Kuliah Hidrologi. Sorong

Wesli, 2008. Drainase Perkotaan, Yogyakarta: Penerbit Graha Ilmu. 